\title{
Mercado del suelo urbano y reserva financiera de terrenos para producción de vivienda en el Área Metropolitana de Santiago ${ }^{1}$
}

\author{
Urban land market and financial reserve of land for \\ housing production in the Metropolitan Area of Santiago
}

\author{
Ivo Ricardo Gasic Klett²
}

\begin{abstract}
RESUMEN
El suelo urbano en Chile se ha ido transformando en un instrumento de inversión e incluso en un espacio de valorización del sector financiero. El presente trabajo aporta evidencia sobre la alta participación de entidades financieras en el mercado del suelo del Área Metropolitana de Santiago entre 2010 y 2015. A su vez, mediante un trabajo de estadística descriptiva y una sistematización de agentes implicados en el desarrollo inmobiliario de casas, se detecta que bancos y aseguradoras son agentes clave en la formación de reservas de suelo. Estas entidades operan normalmente bajo instrumentos de arriendo financiero de terrenos, los cuales permiten entregar liquidez a las empresas inmobiliarias y/o anticipar las adquisiciones para proyectos de vivienda a mediano y largo plazo. Este trabajo culmina discutiendo los efectos de esta práctica financiera sobre el precio y la disponibilidad de suelo asequible, contribuyendo a una reflexión crítica sobre el carácter socialmente excluyente del mercado del suelo urbano.
\end{abstract}

Palabras claves: mercado del suelo urbano, reservas financieras, producción inmobiliaria.

\begin{abstract}
The urban land in Chile has been transformed into an investment tool and even a financial asset. The present work provides evidence on the high participation of financial institutions in Santiago Metropolitan Area's land market, between 2010 and 2015. Also, through a descriptive statistical work and a systematization of agents involved in the real estate development of houses, is detected that banks and insurers are key agents in the formation of land reserves. These institutions normally operate under land lease instruments, which provide liquidity to real estate companies and / or anticipate acquisitions for medium and long term housing projects. This work concludes by discussing the effects of this financial practice on the price and availability of affordable land, contributing to a critical reflection on the social exclusionary character of the urban land market.
\end{abstract}

Palabras claves: urban land market, financial reserves, real estate development. 
El mercado del suelo es un mercado de activos, no de bienes ni servicios. Su precio se forma a partir de dos fundamentos: las rentas del suelo y la tasa de interés. Desde el punto de vista de las rentas, la teoría económica clásica señala que éstas se deducen de los precios de las mercancías finales que sobre el suelo se producen (Smith, 1981; Marx, 1981; Ricardo, 1985); y asimismo la oferta de suelo no se determina por el proceso de producción sino por la demanda (Jaramillo, 2009). De esta forma, suponiendo que el mercado del suelo se determina por la demanda, la mayoría de los investigadores explican el precio del suelo a partir de los ingresos de la población, donde destaca el trabajo empírico de larga data recientemente publicado por Knoll, Schularick \& Steger (2014).

Para el caso de estudio del presente trabajo, el Área Metropolitana de Santiago (AMS), Chile, la Figura $\mathrm{N}^{0} 1$ muestra la covariación del ingreso autónomo de los hogares urbanos y el precio del suelo promedio ofertado. Si bien ambos aumentan de manera notoria, las inflexiones en el precio del suelo son mayores y obedecen a los distintos ciclos del desarrollo inmobiliario en el AMS, creciendo más que los ingresos durante el boom inmobiliario del período "entrecrisis" que va desde 1999 a 2008. Mientras tanto, el comportamiento de los ingresos muestra una tendencia larga de crecimiento sostenido incluso desde algunos años antes del inicio de esta serie de datos. Si bien no se expresa una relación causal, la Figura N01 sirve para graficar dos variables que crecen con cierta simultaneidad, llegando a ingresos autónomos de hogares sobre los USD 20.000 y precios del suelo sobre los $250 \mathrm{USD} / \mathrm{m}^{2}$

Contextualizando, el mercado del suelo en el AMS responde a las dinámicas inmobiliarias generales de un país que ha experimentado radicales cambios económicos y sociales en su última fase de reestructuración capitalista (De Mattos, 2016). Después de una década de los noventa creciendo al 7\%, con alta estabilidad macroeconómica (De Gregorio, 2005), y con un fuerte incremento en un $150 \%$ del PIB per cápita nacional entre 1990 y 2015, la década de los 2000 -poscrisis asiática- ve nacer en el AMS un mercado inmobiliario más determinado por el aumento en el ingreso de grupos medios y altos que por el aumento en la demanda agregada de una población metropolitana que crece al $1 \%$ anual ${ }^{3}$ y con corrientes migratorias marginales salvo los flujos internacionales de los últimos cinco años.

Aunque la formación de nuevos hogares no ha descendido tanto como la población, lo cual evita una caída mayor en la demanda. Esto debido a la reducción del tamaño de los hogares, que ha llegado a un $58 \%$ de hogares con solo un hijo y $80 \%$ de hogares con cuatro o menos integrantes. 
Figura N01. Variación del precio del suelo ofertado en Santiago y del Ingreso Autónomo de los Hogares Urbanos de la Región Metropolitana.

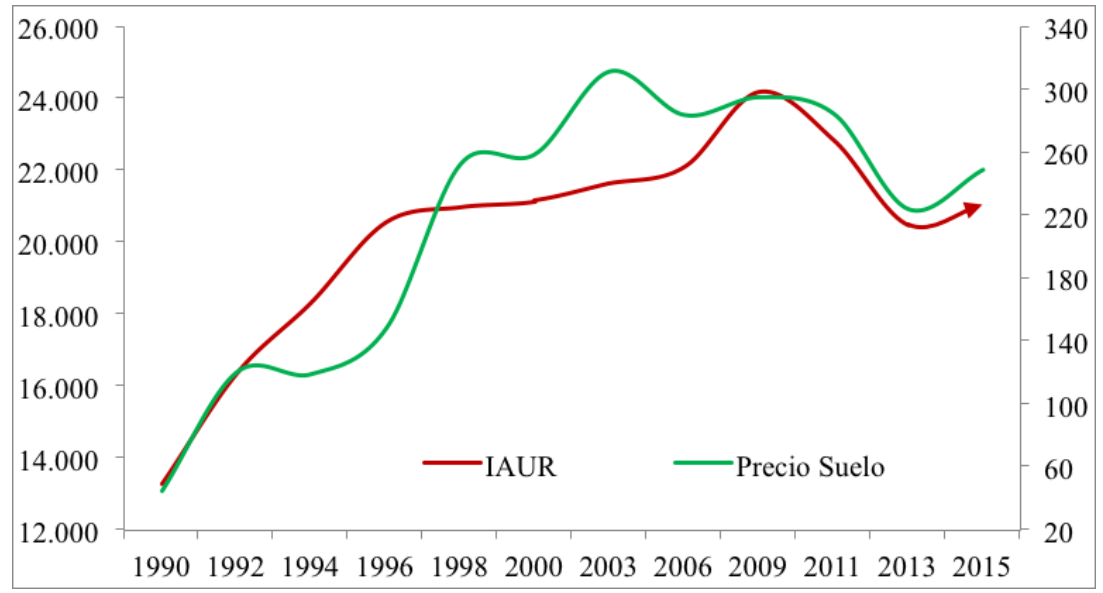

Fuente: elaboración propia (2018) en base a datos de Banco Central y Pablo Trivelli y Cía Ltda. Valores en USD al 01-11-2017.

Lo dicho hasta ahora es solo parcialmente cierto. Ocurre que en contextos como el chileno, con alta penetración del sector financiero y de inversionistas, el suelo pasa a transformarse en un activo de inversión (Edwards et al., 1995), y por ende el comportamiento del precio comienza a depender de los indicadores del sector financiero (arbitraje propio del sector: tasas de interés, colocaciones en bonos y acciones, etc.), estableciendo relaciones inversas entre precio del suelo y tasas de interés ${ }^{4}$ (Jaramillo, 2009). Esta situación, en conjunto con la dinámica de financiarización de la demanda, explica la alta inversión en activos inmobiliarios y el incremento del precio del suelo en aquellos países que han atravesado "booms" inmobiliarios como Estados Unidos, Reino Unido, España, entre otros. El trabajo de Hudson (2011) muestra elocuentemente cómo previo a la crisis de 2008 el incremento en el precio del suelo ${ }^{5}$ del total de las propiedades en Estados Unidos llegó a los USD 2,5 trillones superando largamente los USD 1,5 trillones de ganancias del total de las empresas en el país, resultando a los inversionistas más atractivo invertir en activos inmobiliarios que en empresas productivas (Hudson, 2011).

A su vez, la inversión financiera en suelo urbano no solo se explica por la formación de burbujas asociadas a la expansión de la demanda inmobiliaria corriente. Dado que el suelo urbano es la principal condición de producción del sector inmobiliario, las empresas de desarrollo inmobiliario tienden a generar reservas de suelo -que en el rubro denominan "bodegaje de terreno"- según sus requerimientos a corto, mediano y largo plazo, dependiendo del tamaño de la empresa y su cartera de proyectos a ejecutar. Y en ese proceso de capitalización del suelo es posible observar la formación de un conglomerado inmobiliario-financiero dedicado a la adquisición de terrenos para proyectos futuros, lo que asegura la disponibilidad de éste y anticipa su valorización (Gasic, 2018).

Precio del Suelo = Renta del Suelo / Interés

Considerado como proxy de las ganancias de capital en bienes raíces. 
En síntesis, lo que se ha planteado es que: 1) el suelo urbano tiene la particularidad de no ser producido y, por ende, la demanda crea el mercado y sus precios; 2) observando la demanda, en el AMS el mercado del suelo se determina menos por volumen y más por la dinámica de los ingresos medios y altos; 3) la demanda que explica el mercado puede no ser la actual dado que empresas y fondos financieros reservan terrenos para proyectos futuros, lo que puede alterar de manera importante el mercado del suelo cuando hay exceso de capital, bajas tasas de interés, etc.

Considerando estos factores, el presente trabajo investiga las adquisiciones de terrenos que realizan empresas inmobiliarias, sociedades de inversión y entidades financieras en el AMS, sosteniendo la hipótesis de que logran constituir reservas de terrenos con impacto sobre el precio y la disponibilidad de suelo para vivienda social y otros usos socialmente eficaces. A continuación se muestran los resultados del trabajo bajo el siguiente orden: 1) contexto de la financiarización inmobiliaria y del suelo urbano en Chile, con énfasis en el AMS; 2) materiales y método utilizado para el análisis de transacciones en el mercado del suelo; 3) principales resultados; 4) reflexiones de cierre y discusión de resultados.

\section{Desarrollo del financiamiento inmobiliario en Chile}

El crecimiento de los ingresos de los segmentos medios y altos de la población en el AMS explica parte del comportamiento sostenidamente alcista del precio de la vivienda -y del suelo urbano, consecuentemente-, el cual registra un incremento de $75 \%$ entre 2004 y $2016^{6}$, llegando a 167.500 USD el precio medio de la vivienda al 2016. No obstante, en este aumento sostenido de los precios y activación del mercado inmobiliario, sobre todo en el período "entrecrisis" (20002008), no solo ha influido el factor ingresos. A ello se suma una creciente disponibilidad de financiamiento tanto a la demanda como a la oferta. Por el lado de la demanda, el descenso de las tasas de interés de los créditos hipotecarios de 4,9\% a 3,5\% entre 2004 y 2016 y la consecuente masificación de estos instrumentos ${ }^{7}$ ha implicado un creciente endeudamiento de los hogares (López Morales, 2016), aunque por debajo de los niveles de los países europeos y del resto de la OCDE (Cox y Parrado, 2005; OCDE, 2015).

De esta forma, como se comentó anteriormente, parte de la lógica contemporánea del mercado inmobiliario consiste en una relativa autonomía de los precios respecto de los ingresos presentes de la población local, dado el creciente proceso de financiarización inmobiliaria (Aalbers, 2016 , 2018). Por esta razón es necesario revisar los antecedentes clave que permiten comprender la gestación y el desarrollo de los sistemas de financiamiento inmobiliario, más aún en Chile que es el primer país de América Latina y el Caribe -desde ahora ALC- en abrir sus mercados financieros después del período de "represión financiera" (FMI, 2005).

De hecho, el inicio de las reformas financieras en Chile fue casi inmediato a la llegada de la dictadura militar (1973-1989), aunque con constantes ajustes macroprodenciales que han permitido a esta pequeña economía presentar altos niveles de modernización del sector financiero en

Según el Índice Real de Precios de la Vivienda de la Cámara Chilena de la Construcción.

Posicionándose como una de las principales colocaciones del sector bancario en Chile con casi un tercio de la participación en el total de colocaciones. 
relación al resto de las economías de la región (CEPAL, 2018). La primera medida adoptada por el régimen fue la liberalización de las tasas de interés y la proliferación de la banca libre en 1974, que consistió en relajar la exigencia mínima de capital para conformar sociedades de intermediación financiera, permitiendo a su vez el ingreso de la banca extranjera (CEPAL, 1990). Luego, entre 1975-1978 se privatizaron bancos y se licitaron paquetes accionarios de bancos estatales, conformando un mercado de capitales para la banca estatal no privatizada (Held \& Jiménez, 2001).

La expansión de las colocaciones de bancos y sociedades financieras fue dramática entre 1975-1982, creciendo de $8 \%$ a $73 \%$ las colocaciones totales sobre el PIB nacional en estos siete años (Held \& Jiménez, 2001), las cuales se realizaron a tasas extraordinariamente altas llegando a tasas de 40\% entre 1976-1987 y 30\% entre 1981-1982 (CEPAL, 1990). Luego en 1982 la situación financiera del país se volvió especialmente frágil, a consecuencia de la fuerte revaluación del dólar que golpeó a las instituciones financieras que mantenían deudas en dólares. El conocido Shock Volker realizado por la Reserva Federal de EEUU en 1979 ha sido hasta la fecha la operación más drástica de la historia en lo que respecta a control de la inflación -y consecuente revaluación del dólar-, haciendo que toda la deuda externa de los bancos que operaban en Chile se disparase, golpeando severamente su liquidez y la macroeconomía del país (Ffrench-Davis, 2018), lo que fue extensible a la mayoría de los países de la región y dio paso a los posteriores ajustes estructurales de la denominada "década perdida de América Latina" (Bértola \& Ocampo, 2013).

Tras la crisis de 1982 se inició una gestión financiera que dio curso en 1986 a la Reforma a la Ley de Bancos, la cual permitió controlar el riesgo subiendo las tasas de encaje y limitando los créditos de las operaciones bancarias (Reinstein \& Rosende, 2001). Una de las actividades que comenzó a tomar fuerza para los bancos fue su reaparición en el financiamiento a la vivienda, ya que desde los años 30 fueron desplazados por las cajas de ahorro y luego por las Asociaciones de Ahorro y Préstamo, las cuales dejaron de operar precisamente en el marco de la crisis de la deuda (Morande \& García, 2004).

También posterior a la crisis de 1982 comienza a tener impacto la entrada en vigencia de las nuevas Administradoras de Fondos de Pensiones creadas en 1980, las cuales bajo el principio de capitalización individual han alimentado el mercado de capitales del país, participando desde su origen de la compra de letras hipotecarias a los bancos (Morande \& García, 2004). Y a su vez, en 1989 se crean los Fondos de Inversión, los cuales permiten a su vez la intermediación en base a aportes que pueden ir dirigidos al sector inmobiliario a través de la conformación de sociedades para desarrollo, renta o plusvalía inmobiliaria. De esta manera, como puede verse, tras la crisis de 1982 se habilita un sistema de financiamiento con incidencia en la vivienda compuesto por bancos, AFP y Fondos de Inversión que dura hasta la fecha, aunque con algunas modificaciones e ingreso de nuevos actores.

Precisamente también en 1982 es cuando se registra en Chile un despegue sostenido en la construcción de viviendas. Mientras la edificación anual de vivienda se mantuvo en torno a a $300.000 \mathrm{~m}^{2}$ entre 1940 y 1957, luego aumenta drásticamente en el período 1959-1981 pero con fuertes oscilaciones, que van desde los 2 millones de $\mathrm{m}^{2}$ autorizados en 1959 a los 4 millones de

Según Held \& Jiménez (2001) estas altas tasas en los créditos otorgados a las empresas nacionales, fundamentalmente primario-exportadoras, se explican por el nivel de desfinanciamiento de las empresas privadas productivas del país en los años previos a 1973. 
$\mathrm{m}^{2}$ registrados en los peaks de 1970 y 1981. Esto se debió a la fuerte migración campo-ciudad y a las posteriores políticas y legislaciones orientadas a resolver el déficit que estos movimientos migratorios generaron ${ }^{9}$. Luego de este período de aumento oscilatorio en el volumen de edificación de vivienda, que acaba con un valle en 1982 por debajo de los 2 millones de $\mathrm{m}^{2}$, se inicia un período de crecimiento estable ${ }^{10}$ desde 1983 hasta la fecha, solo interrumpido por los shock externos de la crisis asiática y subprime.

De esta forma se observa una convergencia pos crisis 1982 de una articulación entre nuevas instituciones financieras y una pujante actividad inmobiliaria -al menos en volumen construido. Desde inicios de los años 80 los diversos agentes e instituciones que han ingresado al financiamiento inmobiliario -tanto por el lado de la demanda como por el lado de la oferta/producciónhan logrado aumentar la capitalización inmobiliaria y reforzar el sistema bancario basado en créditos hipotecarios. En resumen, siguiendo lo dicho, se puede observar desde 1982 las siguientes entidades financieras con incidencia en el sector inmobiliario especialmente de vivienda:

1) establecimiento del sistema de pensiones y particularmente de las Administradores de Fondos de Pensiones (AFP), que bajo el principio de capitalización individual han abierto múltiples canales para transformar el ahorro en capital prestable, incidiendo de forma indirecta en un volumen muy considerable de la producción de vivienda. Los fondos de pensiones han comprado históricamente más de un $40 \%$ de las letras hipotecarias y además han invertido cerca de USD 520 millones en cuotas de fondos inmobiliarios"11, logrando ser uno de los principales inversionistas institucionales en el sector inmobiliario, al igual como ocurre en varios países europeos (Theurillat, 2012).

2) creación de los Fondos de Inversión Inmobiliaria inicialmente pensados para estimular un segmento de pequeños inversionistas pero, luego, utilizados por los desarrolladores inmobiliarios como fondos para capitalizar el sector con mayores ventajas tributarias. Los datos de Cattaneo (2011) muestran que los fondos inmobiliarios han impulsado obras por casi 21.000 unidades, es decir, un $8,7 \%$ del total de permisos de edificación emitidos para esos cinco años. Vale notar que en el mercado de vivienda se han enfocado en el desarrollo de proyectos y no en el negocio de la renta, y en lo que respecta a inversión en suelo es deducible baja participación dada la escasa actividad de los fondos de plusvalía, que entre 2004 y 2016 disminuyen su fondo administrado en un 63\%, pasando de administrar 67.000 millones de pesos en 2004 a un total de 24.500 millones de pesos en $2016^{12}$.

3) incremento sustantivo de la participación de las Compañías de Seguros de Vida (CSV) en la inversión inmobiliaria directa, además de la compra de letras hipotecarias. Las aseguradoras en Chile han registrado un aumento significativo en activos inmobiliarios al menos desde mediados de los años 2000. Entre 2005 y 2014 han invertido anualmente un pro-

\footnotetext{
La más destacable de estas medidas fue la aprobación del D.F.L.-2 en 1959, además de la creación del MINVU en 1965. Con todo, el período 1959-1981 es reconocido como un período de activación del sector de la construcción habitacional en el país.

10 Desde 1983 se ha registrado solo dos grandes interrupciones: entre 1997-2002, posterior a la crisis asiática que impactó fuertemente al país, y en 2009-2010 posterior a la crisis financiera global. Ambos shocks externos han sido los únicos eventos que han deformado la curva de crecimiento sostenida en la construcción de viviendas.

Información de la Asociación de Administradoras de Fondos de Pensiones de Chile, citada en De Mattos (2013).

Según datos de la Asociación Chilena de Administradoras de Fondos de Inversión (ACAFI).
} 
medio de 100 millones de UF, cerrando al 2014 con 162 millones de UF, monto superado solamente por la inversión en "Bonos y Debentures"13. Su aumento del $80 \%$ en inversiones inmobiliarias entre esos años corresponde a uno de los mayores incrementos en la cartera total de inversiones de las aseguradoras, pasando a ser importantes capitalizadores del sector inmobiliario en inversiones directas a diferencia de las AFP y bancos que deben seguir cursos indirectos a través del mercado de valores y capitales.

De lo anteriormente comentado, se puede concluir una mayor integración de los capitales financieros e inmobiliarios en Chile, superando la lógica inicial de articulación directa entre los sectores inmobiliario y bancario. Esta penetración del sector financiero se comprende desde la creación de las AFP a inicios de los años 80 , la creación de los distintos fondos de inversión inmobiliaria a fines de la misma década y la inversión inmobiliaria directa de las compañías de seguros de vida intensificada en los años 2000. Este contexto general permite situar la mercantilización del suelo urbano dentro de un proceso de apertura financiera en Chile, lo que invita a estudiar con mayor detenimiento la lógica financiera del mercado del suelo del AMS. Para ello es necesario primero revisar algunos planteamientos y evidencias reportadas por anteriores investigaciones.

\section{Planteamientos y evidencias sobre la lógica financiera del mercado del suelo en Chile}

A principios de los años 80 Sabatini y Donoso $(1979 ; 1980)$ formularon la tesis de la conformación de reservas de suelo por parte del pujante sector financiero del país. Esa tesis señalaba que en los años 80 se liberalizaría el suelo urbano y agentes de carácter financiero pasarían a tomar posición en el control de la propiedad inmobiliaria. Efectivamente, entre 1974 y 1979 se aprobaron sucesivos cambios regulatorios y tributarios para facilitar el ingreso de inversionistas, lo que acompañado de la liquidación de las reservas estatales de suelo (Sabatini y Donoso, 1979) inauguró una fase de predominio del conglomerado inmobiliario-financiero en el control de la propiedad de la tierra de Santiago. Estas medidas culminaron con la aprobación en 1979 de la Política Nacional de Desarrollo Urbano que definiría al suelo urbano como un bien no escaso, y ampliaría desmesuradamente el límite urbano de Santiago.

En ese sentido es pertinente lo que señalan Sabatini y Donoso (1979; 1980): desde los años 80 en adelante el ingreso de nuevos inversionistas al mercado del suelo sería inminente e inaudito para la historia de la ciudad. Sin embargo, ¿se trata necesariamente de "entidades financieras"? ¿Entran a comprar suelo las antiguas empresas constructoras que requerían nuevos terrenos para sostener su industria? ¿qué características tienen las empresas y sociedades inmobiliarias que ingresan al mercado del suelo y bajo qué expectativas de rentabilidad operan? ¿Qué relación pueden tener con el proceso generalizado de crecimiento del sector financiero en el país?

Con estas preguntas todavía abiertas, en anteriores trabajos (Gasic, 2016, 2018) se ha indagado sobre la evidencia empírica que existe para, al menos, sostener la idea de que el sector financiero participa del mercado del suelo y de que se trata de un sector financiero complejo, con

13 Según datos de la ex Superintendencia de Valores y Seguros, actual Comisión para el Mercado Financiero (CMF). 
distintos agentes y relaciones diversas con el empresariado inmobiliario. Los datos que arroja la investigación de Gasic (2018) muestran que, de las 19.800 adquisiciones de suelo realizadas en el AMS entre 2010-2015, 2.900 corresponden a entidades de intermediación financiera, que se traducen en un aproximado de 2.760 hectáreas (33\% del total de suelo transado). Si se considera que un informe de gobierno estima el crecimiento urbano del AMS entre 2011-2018 en torno a 2.570 hectáreas anuales (CEHU, 2013), la superficie adquirida por entidades financieras representa un $18 \%$ de la superficie de suelo agregado a la ciudad en un año.

Más sorprendente aún es notar que las entidades financieras compran incluso más suelo que las entidades del rubro inmobiliario propiamente tal, constituyéndose como el principal comprador de terrenos del AMS al menos entre 2010 y 2015 . Si bien en cantidad de transacciones la mayoría de los terrenos son adquiridos por personas naturales, en términos de superficie adquirida los predios de éstos son mucho más pequeños, por lo cual representan un $24 \%$, 4 puntos porcentuales más que las actividades inmobiliarias y 8 puntos porcentuales menos que las entidades financieras. La Figura $N^{\circ} 2$ presenta estas proporciones en un gráfico de área de participación sobre el total de 8.240 hectáreas transadas en los seis años de estudio.

Figura No2. Participación de sectores económicos (según Rubros SII) en el total de 8.420 hectáreas de suelo transado el AMS, 2010-2015.
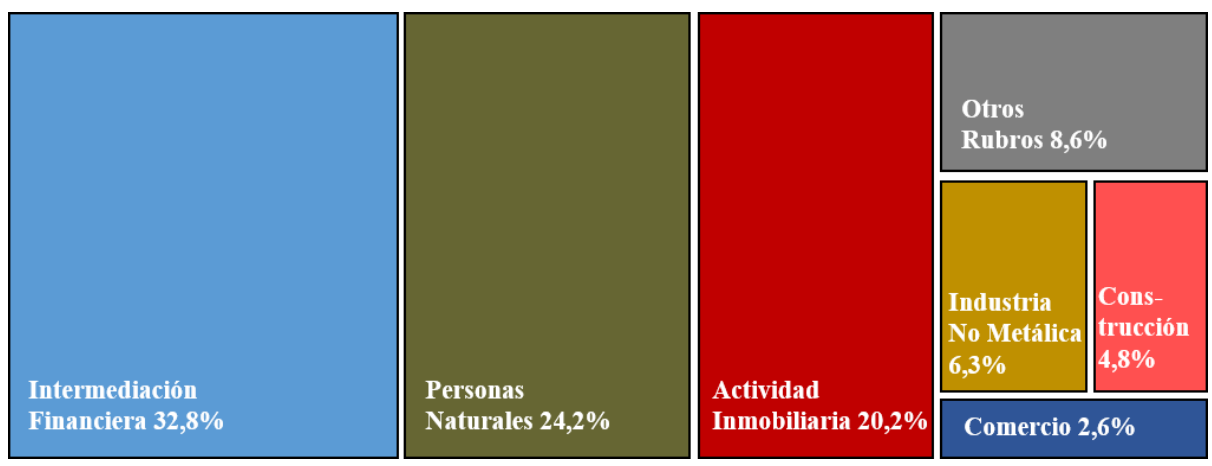

Fuente: elaboración propia en base a datos de Conservadores de Bienes Raíces de la Región Metropolitana (2017).

Sin embargo, dentro de las empresas y sociedades agrupadas como "intermediación financiera" se alojan diferencias substantivas entre lo que se podría denominar como entidades "inversionistas" y "financieras". Esto dado que dentro del rubro de intermediación financiera se encuentran sociedades de inversión, bancos y aseguradoras; de los cuales los primeros son los que más participan del mercado (12\% sobre el total), mientras aseguradoras y bancos le siguen con participaciones similares en torno al $4 \%$ y $3 \%$ sobre el total, respectivamente. En cuanto a inversión anual en terrenos en el período 2010-2015, las sociedades de inversión ascienden a USD 1.100 millones, mientras bancos y aseguradoras invierten anualmente USD 544 millones y USD 538 millones respectivamente. El Cuadro N01 muestra un resumen de los datos anualizados comparativos entre sociedades de inversión, aseguradoras y bancos. Se observa una diferencia substantiva en el precio unitario de los terrenos comprados, donde las aseguradoras $\left(785 \mathrm{USD} / \mathrm{m}^{2}\right.$ ) compran terrenos más caros que los bancos $\left(650 \mathrm{USD} / \mathrm{m}^{2}\right)$ y, éstos, más caros que las sociedades de inversión (480 USD/m²). 
Cuadro N¹. Resumen de adquisiciones de terrenos según tipo de entidad financiera.

Datos anualizados.

\begin{tabular}{|l|c|c|c|}
\hline & Inversionistas & Aseguradoras & Bancos \\
\hline Adquisiciones & 294 & 105 & 76 \\
\hline Superficie promedio (ha) & 0,82 & 1,5 & 1,1 \\
\hline Sup. Total adquirida (ha) & 229 & 68 & 84 \\
\hline Inversión (millones de USD) & 1.109 & 538 & 544 \\
\hline Precio del Suelo (USD/m ${ }^{2}$ ) & 480 & 785 & 650 \\
\hline
\end{tabular}

Fuente: elaboración propia en base a datos de Conservadores de Bienes Raíces de la Región Metropolitana (2017).

Considerando estos antecedentes el presente trabajo estudia la articulación del mercado del suelo con la producción de vivienda en el AMS, comprendiendo las lógicas de capitalización del suelo por parte del sector inmobiliario-financiero. Considerando que este sector compra más del $50 \%$ del suelo transado entre 2010 y 2015 , se infiere un impacto relevante en la formación del precio y la disponibilidad de suelo asequible en el mercado. En particular, se observará el proceso de integración de terrenos al desarrollo de los proyectos de vivienda y se analizará el rol de las entidades financieras en la provisión de suelo, en términos de impacto sobre el precio y el tiempo de retención de las propiedades.

\section{Materiales y método}

Para atender el objetivo propuesto se ha seguido un método de carácter estrictamente exploratorio consistente en un análisis longitudinal de integración de terrenos al desarrollo inmobiliario privado (Gasic, 2016), haciendo seguimiento temporal de las distintas inscripciones de propiedad de aquellos terrenos que han sido utilizados para la conformación de paños de desarrollo inmobiliario habitacional.

Para esto se comenzó realizando una caracterización de las principales empresas inmobiliarias en Santiago en el período 2010-2015. La fuente utilizada fue una base de datos provista por la empresa Inciti Consultores, que comprende un registro completo de la oferta y la venta de unidades habitacionales en Santiago, especificando tipo de vivienda, programa, precio, superficie y otros datos relevantes para la descripción estadística del desarrollo inmobiliario habitacional metropolitano. Este registro contempla la totalidad de los proyectos con unidades habitacionales a la venta entre 2010 y 2015. Con un total de 2.375 proyectos habitacionales, 1.531 de departamentos y 844 de casas, se ha logrado confeccionar una base de datos con representatividad estadística, que sirve a este trabajo para identificar a los principales desarrolladores inmobiliarios de producción de vivienda nueva en Santiago.

Para seleccionar a estas empresas se tomaron cuatro indicadores: cantidad de proyectos ejecutados, cantidad de unidades habitacionales, superficie total producida y volumen total de ventas en el período. Se estratificó a las empresas según estos cuatro indicadores y se identificaron los quiebres naturales en la serie de datos, lo que permitió seleccionar a aquellas empresas con 
mayor participación en cada uno de los indicadores. A partir de la identificación de los desarrolladores inmobiliarios con mayor participación en el mercado de vivienda se continuó el trabajo solo con aquellas empresas dominantes en el sub-mercado de casas. El motivo por el cual se trabajó solo con este sub-mercado es porque se supone que presenta períodos de valorización, incorporación y gestión del suelo más largos y con mayor incidencia sobre la disponibilidad de suelo para vivienda social.

A su vez se remitió el estudio a los proyectos habitacionales localizados en lo que se denomina "periferia urbana consolidada", esto es, el arco de comunas periféricas dentro del AMS donde se ubica el suelo disponible para la expansión continua de la ciudad. Esta categoría espacial es relevante, además, porque ahí se ubica buena parte de la vivienda social radicada hasta inicios o mediados de los años 2000, como lo muestra la figura anterior; y porque se localizan nuevos proyectos inmobiliarios que han ido desencadenando alzas de precios (Trivelli, 2011) que han forzado a la expulsión de los hogares ahí localizados hacia el periurbano exterior al AMS.

Por motivos de disponibilidad de datos históricos únicamente para el Conservador de Bienes Raíces de Santiago, y no así para los otros tres conservadores del AMS, se ha trabajado entonces solo con las comunas de Huechuraba, Quilicura, Renca, Pudahuel, Maipú, La Florida y Peñalolén. Se realizó una muestra intencionada de proyectos de casas ejecutados por los desarrolladores inmobiliarios dominantes en el mercado y localizados en este conjunto de comunas.

A los proyectos inmobiliarios seleccionados se les aplicó una Técnica de Encadenamiento Predial (Gasic, 2016), que consiste en realizar un seguimiento histórico, más bien longitudinal, a los predios que conformaron el paño final de terreno sobre el que se ejecutó cada proyecto. En este sentido, la Técnica de Encadenamiento Predial sirve para observar el conjunto de transacciones y propietarios que han aportado a la incorporación de terrenos al desarrollo inmobiliario. El encadenamiento de los predios se ejecuta a partir de la inscripción de propiedad de alguna de las unidades habitacionales vendidas por el desarrollador inmobiliario, y sobre ella se realiza una búsqueda en los archivos digitales del Conservador de Bienes Raíces de Santiago. Se reportan los tipos de agentes económicos, los diferenciales de precio y los tiempos de retención de los terrenos.

Estos datos han sido empleados en este trabajo con fines puramente descriptivos, intentando proveer de información privada de difícil acceso que usualmente no se considera en los estudios sobre el tema. Con ella se logra una profusa descripción de las formas en las cuales los desarrolladores inmobiliarios penetran sobre el mercado del suelo y las estrategias de articulación o complementariedad que logran con agentes financieros e inversionistas.

\section{Selección de la muestra}

Al revisar los 844 proyectos habitacionales de casas mantenidos en oferta en el período 20102015 en Santiago, se aprecia una cantidad significativa de 259 promotores inmobiliarios, destacándose el gran número de ellos participando del mercado, cuestión que se extiende para el caso de los departamentos, como muestra el Ranking de Promotores Inmobiliarios de Inciti (2016). Nótese que se emplea el término "promotores" y no "empresas" ya que metodológicamente han sido individualizados a través del nombre de marca y no de la razón social. 
Es cierto que no siempre se trata de actores distintos en el mercado, ya que es posible que existan empresas relacionadas -filiales y coligadas- de grupos inmobiliarios matrices que individualizan las entidades por motivos exclusivamente tributarios, regulatorios o de diversificación del riesgo en caso de financiamiento externo. Pero aun así es necesario destacar que, si las figuras jurídicas son independientes y tienen estructuras de financiamiento también diferenciadas, la forma en que se penetrará en el mercado del suelo será más flexible, atomizada, fragmentaria, entre otras.

El Cuadro No2 muestra una estratificación de las inmobiliarias con mayor-menor participación según cuatro variables, generando cuartiles que representan desde el $25 \%$ de las inmobiliarias con menor participación (primer cuartil) hasta el 25\% de las inmobiliarias con mayor participación (cuarto cuartil). Se observa que hasta los dos primeros cuartiles (50\% de las empresas) las inmobiliarias tienen solo un proyecto -lo que se comentó anteriormente- y no sobrepasan las 65 unidades ofertadas. Recién en el tercer cuartil hay un aumento sustantivo en unidades, superficie y venta.

En el cuarto cuartil, es decir, donde se ubica el 25\% de empresas con mayor participación, la situación cambia radicalmente. En este cuartil es posible observar que el rango de producción de las empresas se extiende sustantivamente, donde la empresa con mayor producción en todas las variables totaliza 73 proyectos ejecutados, 5.027 unidades producidas, $509.151 \mathrm{~m}^{2}$ de superficie y casi 19 millones de UF ${ }^{14}$. Nótese que, al observar el rango total, desde la empresa más pequeña a la más grande según cada variable, el factor multiplicador llega incluso hasta casi los 2.500 (en el caso de las ventas).

Cuadro No2. Estratificación de inmobiliarias por cuartiles según cuatro variables de participación en mercado.

\begin{tabular}{|l|c|c|c|c|}
\hline Cuartil & Proyectos & Unidades & Superficie $\left(\mathrm{m}^{2}\right)$ & Venta (UF) \\
\hline Primer & 1 & 17 & 2.526 & 125.211 \\
\hline Segundo & 1 & 65 & 7.212 & 263.502 \\
\hline Tercer & 2 & 213 & 18.655 & 612.804 \\
\hline Cuarto & 73 & 5.027 & 509.151 & 18.790 .650 \\
\hline Rango Total & $1-73$ & $4-5.027$ & $424-509.151$ & $7.552-18.790 .650$ \\
\hline
\end{tabular}

Fuente: elaboración propia a partir de Inciti (2016).

Es necesario considerar que, para el caso de los departamentos (que aquí no se detalla), la estratificación muestra un comportamiento muy similar a la recién comentada (Inciti, 2016). Por tanto, de conjunto, se observa un mercado habitacional con un gran espectro de promotores de participación marginal que homogeneiza los tres primeros cuartiles, dejando un cuarto cuartil con amplio rango, donde existen ciertos promotores que logran escalas de producción notablemente superiores. Para identificar a este grupo de promotores dominantes, se ha seguido la estratificación precedente y se ha observado el primer y más importante quiebre natural en la serie de

La UF es una unidad de cuenta utilizada en Chile, autoajustable de acuerdo con la inflación. Se utiliza ampliamente para valorar activos y fijar precios inmobiliarios, dada la larga duración de estos bienes y la existencia de financiamientos de largo plazo. Actualmente, a $\mathrm{O} 2$ de marzo de 2019, 1 UF equivale a 27.560 pesos chilenos o USD 39,9. 
datos para cada indicador, lo que permite separar a las inmobiliarias del cuarto cuartil y enfocar específicamente en aquellas que se comportan como dominantes en el mercado.

De esta forma, se logró seleccionar un conjunto de diez promotores que protagonizan el mercado de casas en los cuatro indicadores considerados, representando el $40 \%$ de la oferta total de casas en Santiago. En términos relativos, las empresas de este conjunto sostienen participaciones entre $2 \%$ y $5 \%$ cada una, mientras dos de ellas -Aconcagua y Socovesa- sostienen participaciones entre $7 \%$ y $9 \%$ en los cuatro indicadores. Es importante mencionar que estas diez empresas no pertenecen a mismos conglomerados inmobiliarios, por lo que pueden tratarse como entidades independientes entre sí. Observando la Figura $\mathrm{N}^{\circ} 3$, sorprende que los dos principales promotores tienen participaciones bajo el $10 \%$, lo que revela que la estructura de mercado de las empresas inmobiliarias de casas en Santiago dista de los altos niveles de concentración que muestran otros sectores de la industria, el comercio y la explotación de recursos naturales en el país.

De esta forma, las empresas recién comentadas conforman el grupo de desarrolladores inmobiliarios dominantes en el mercado de casas, que interesa para este trabajo en tanto operadores en volúmenes considerables del mercado de terrenos en Santiago. Para efectos de la espacialización de los desarrolladores dominantes, se ha mapeado el conjunto de los proyectos que han ofertado en el período 2010-2015, obteniendo cierta información sobre su comportamiento espacial en Santiago. Ahora bien, del total de proyectos de estas empresas, se ha establecido una muestra cualitativamente significativa de 92 proyectos producidos entre 8 de las 10 inmobiliarias más grandes en producción de casas. De estos proyectos revisados, se ha efectuado un análisis a 28 de ellos, ya que en su mayoría corresponden a etapas de macroproyectos de urbanización y desarrollo de vivienda que han sido individualizados como proyectos para efectos de la base de datos elaborada por Inciti, que registra como proyectos individuales a etapas de un mismo proyecto, toda vez que tengan inicio de ventas separadas por meses.

Figura N³. Principales desarrolladores inmobiliarios de casas en Santiago.

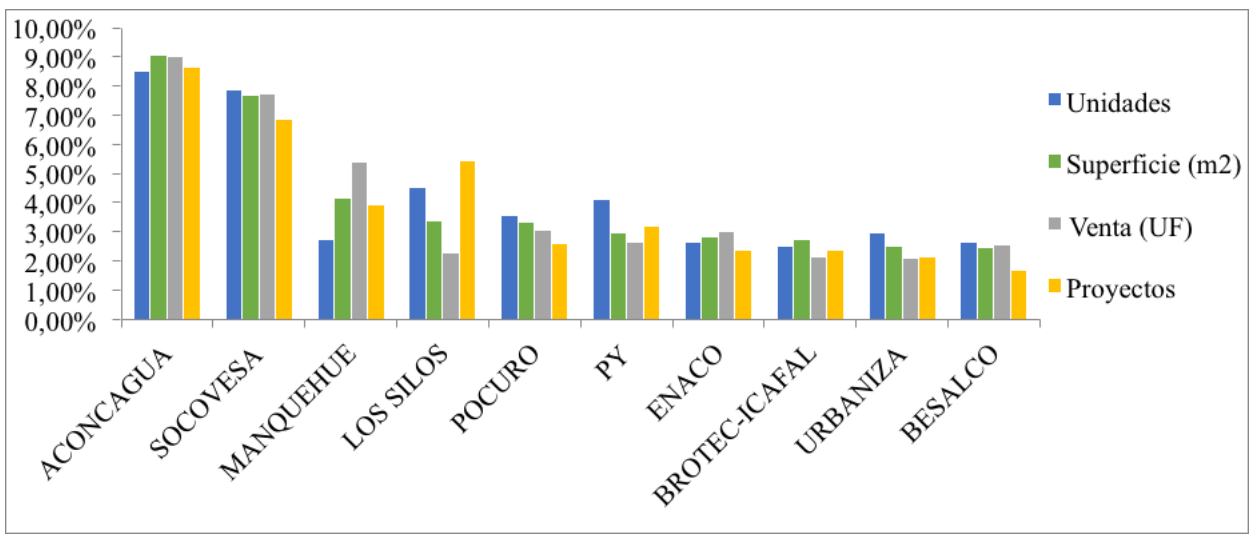

Fuente: elaboración propia en base a Inciti (2016).

Por ello, como el objeto de este análisis es observar los agentes que intermedian los predios y las relaciones que establecen con los promotores inmobiliarios finales que encargan la construcción de las viviendas, se torna innecesario observar los encadenamientos prediales de las 
diferentes etapas que se ubican de forma adyacente ${ }^{15}$. La Figura $N^{0} 4$ grafica el total de 703 etapas de proyectos de casas iniciados entre 2010 y 2015 según la base de datos de Inciti, y la muestra de 28 etapas de proyectos seleccionadas para este análisis. Nótese que se han discriminado las áreas de periurbanización norte y sur, considerando solo los proyectos que forman parte de la periferia urbana consolidada de Santiago.

Figura No4. Mapa de proyectos de casas ofertados en Santiago entre 2010 y 2015.
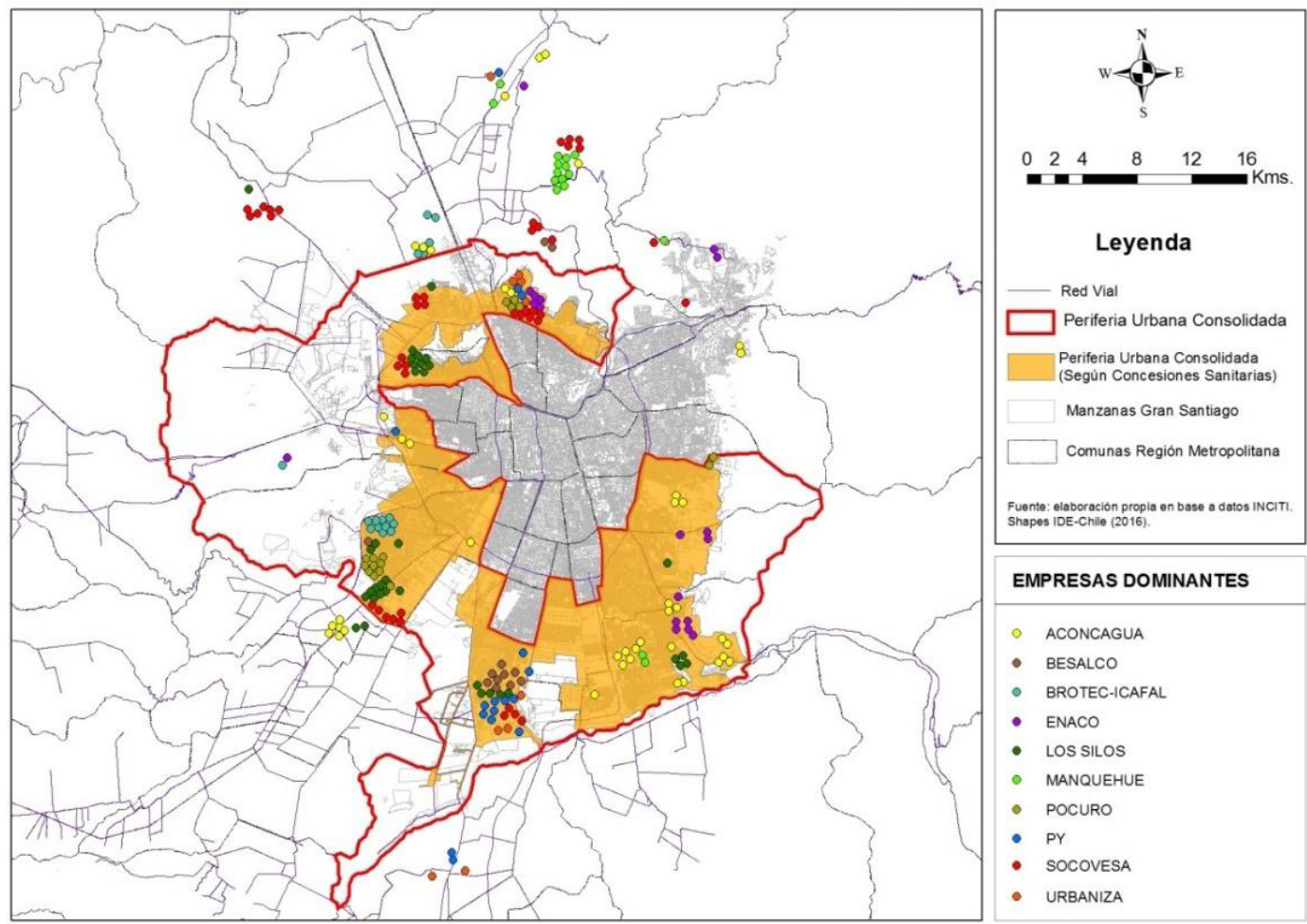

Fuente: elaboración propia con datos de Inciti (2016). Shapes IDE-Chile (2016).

\section{Principales resultados del análisis de terrenos incorporados al desarrollo inmobiliario de casas en el Área Metropolitana de Santiago}

\section{Esquemas de valorización del suelo según intermediaciones financieras y comerciales}

Consistente con lo planteado al inicio de este trabajo, el análisis de los proyectos de casas seleccionados muestra que éstos tienden a ejecutarse sobre terrenos que han sido intermediados

Metodológicamente se ha preferido considerar exclusivamente una etapa de proyecto y así no replicar información correspondiente, por lo general, a una misma operación inmobiliaria de gestión de suelo. 
por uno o más agentes económicos de carácter comercial y financiero, es decir, dedicados a la compraventa de propiedades y al fondeo financiero de las mismas. Solo 7 de los 28 proyectos no presentan intermediaciones, generándose una compraventa directa entre el desarrollador inmobiliario y una persona natural o empresa con uso efectivo del terreno. Clasificando los agentes que intermedian terrenos según actividad económica principal declarada ante el Servicio de Impuestos Internos -SII-, se identifica la presencia de los mismos agentes económicos señalados anteriormente: sociedades de inversión -algunas de ellas vinculadas a fondos de inversión-, bancos, aseguradoras y empresas de leasing financiero.

Al analizar particularmente las relaciones societarias entre las sociedades de inversión y los desarrolladores inmobiliarios, se desprende que dichos inversionistas operan de dos formas: 1 ) como inversionistas especulativos que compran suelo barato y lo revenden a mayor precio, captando una ganancia de capital de tipo comercial; 2) como sociedades relacionadas a los desarrolladores inmobiliarios $y$, por tanto, como agentes que cumplen la función de reservar terrenos para sus propias empresas con precios de transferencia internos y ventajas tributarias asociadas.

La Figura N05 esquematiza las relaciones entre desarrolladores, sociedades de inversión y propietarios de la tierra. En la Figura N05.A se muestra que la demanda de suelo proviene del desarrollador, el cual contribuye con parte de su capital para formar una sociedad relacionada para adquirir el terreno, sea con participación dominante o no. A veces se integra a dicha sociedad el propietario original del terreno, a veces se incorporan otros inversionistas, pero en todos los casos la operación corresponde a una reserva de terreno con participación en el financiamiento por parte del desarrollador y algún otro inversionista.

Figura N05. Esquemas de intermediación de terrenos por sociedades de inversión.

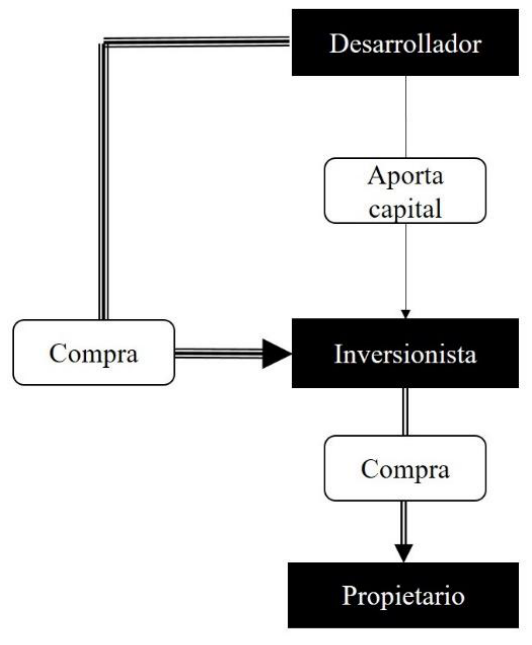

A. Esquema de intermediación entre agentes relacionados

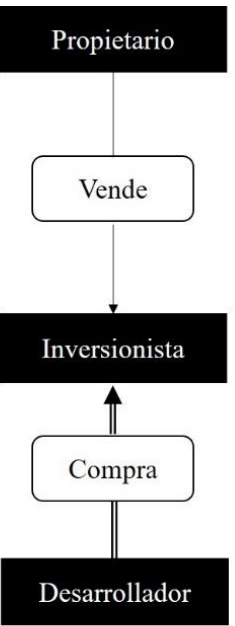

B. Esquema de intermediación comercial

Fuente: elaboración propia (2018). *En negro los agentes, en blanco las relaciones. **Las líneas del esquema son más gruesas cada vez que el proceso de intermediación avanza. ${ }^{* * *}$ El origen de las flechas indica el agente que origina la transacción u operación, dirigiendo el sentido hacia el agente pasivo. 
En el Figura N05.B se aprecia que el movimiento inicial corresponde a una oferta de terreno por parte de un propietario que requiere vender y no tiene tiempo para esperar al mejor comprador de suelo para desarrollo inmobiliario. Por ende, vende el terreno a un inversionista que capta una ganancia de capital al revender el terreno a mayor precio al desarrollador. Este inversionista funciona con mayor exposición al riesgo y opera siguiendo una lógica fundamentalmente comercial, aunque en algunos casos incorpora gestión inmobiliaria en términos de solicitar cambios a la normativa urbanística y realización de mejoras en habilitación del terreno.

A diferencia del caso de los inversionistas, el conjunto de entidades financieras constituido por aseguradoras y bancos corresponden a capitales que compran terrenos tras la evaluación de riesgo de un proyecto inmobiliario determinado, frente al cual el desarrollador le solicita al banco o a la aseguradora que adquiera el terreno y se lo reserve por determinada cantidad de tiempo. Para ello se utilizan instrumentos financieros de leasing y leaseback, que consisten en contratos privados para la entrega de financiamiento a la adquisición de un bien mediante cesión material por parte del propietario al usuario por un plazo determinado, y cuya contraprestación por parte del propietario es un canon de arrendamiento que concede al usuario una opción de compra sobre este bien. Es, en definitiva, un arriendo financiero sobre un bien que, en este caso, corresponde a terrenos.

La diferencia entre ambos es que en el leaseback el propietario original vende el terreno a un intermediador financiero, el que se lo arrienda y luego revende, retornando el terreno a su propietario original al final del contrato (Ver Figura $N^{\circ} 6 . B$ ). En el caso del Leasing el propietario original vende el terreno al intermediador financiero y éste lo arrienda a un tercero, el que finalmente adquiere la propiedad al final del contrato (Ver Figura N6.A). En cualquiera de los dos casos el intermediador financiero -es decir bancos y aseguradoras- retiene por un período determinado los terrenos, arrendándolos y luego vendiéndolos a los desarrolladores inmobiliarios, como se ilustra en los esquemas de la Figura $\mathrm{N}^{\circ} 6$.

Figura $\mathrm{N}^{0} 6$. Esquemas de intermediación de terrenos por entidades financieras.

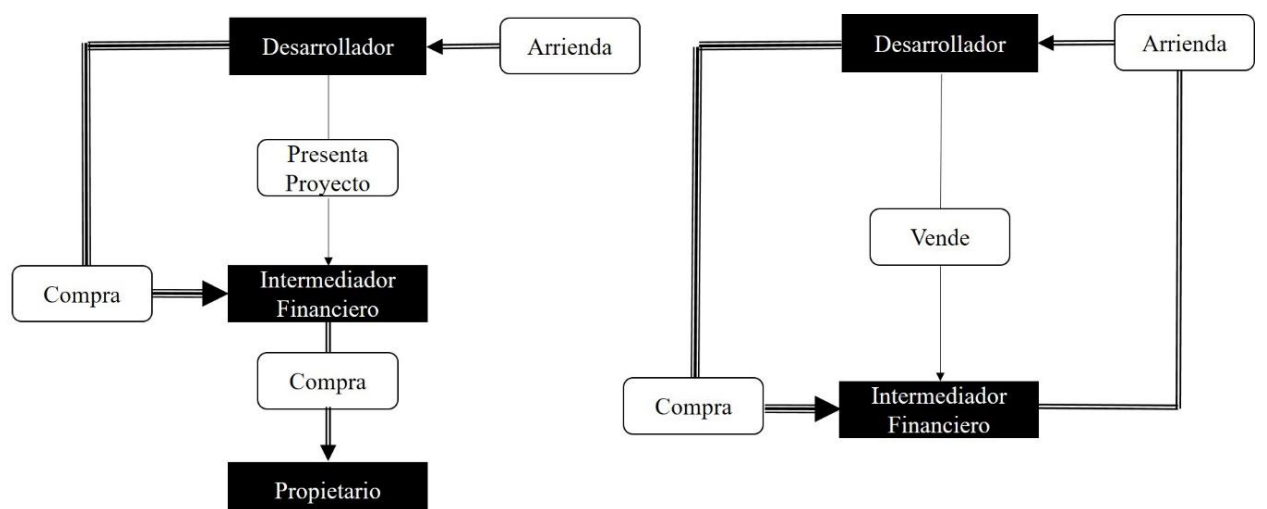

A. Esquema de intermediación mediante leasing

B. Esquema de intermediación mediante leaseback

Fuente: elaboración propia (2018). *En negro los agentes, en blanco las relaciones. ${ }^{* *}$ Las líneas del esquema son más gruesas cada vez que el proceso de intermediación avanza. ${ }^{* \star}$ El origen de las flechas indica el agente que origina la transacción u operación, dirigiendo el sentido hacia el agente pasivo. 
Sobre la creciente importancia del uso de estos instrumentos, los datos de la Comisión para el Mercado Financiero de Chile muestran que en 2008 los activos inmobiliarios en Leasing de las aseguradoras igualaron al resto de activos inmobiliarios en un $5 \%$ sobre el total de activos, mientras al 2016 los Leasing llegaron a 10\% y el resto de activos inmobiliarios se mantuvieron en torno a 5\%. Para el caso de los bancos debe señalarse que la Ley de Bancos en Chile les impide comprar propiedades distintas a aquellas consideradas como garantías propias de la actividad bancaria. Los bancos tienen giro único y ello los limita a adquirir propiedades vía mercado, por lo que están obligados a comprar terrenos solo mediante Leasing. Huelga notar que también por razones regulatorias de la legislación vigente han quedado marginadas de este negocio de intermediación de terrenos las Administradoras de Fondos de Pensiones.

Siguiendo lo anterior, aseguradoras y bancos se constituyen como capital prestable a los desarrolladores inmobiliarios para externalizar sus reservas de suelo, dado el menor costo que presentan ambas entidades para retener su capital en estos activos inmobiliarios por determinados períodos de tiempo. Pero a pesar de que bancos y aseguradoras comparten esta lógica, en el caso de los primeros hay una componente explicativa adicional. Como éstos también otorgan líneas de financiamiento a la construcción, su interés en la ejecución de los proyectos es mayor (Mogrovejo, 2016). Por ello, su interés en la intermediación de los terrenos no es solo la renta del Leasing, sino también el apoyo a la actividad de producción capitalista de viviendas. En caso hipotético, un banco puede estar perfectamente incorporado al desarrollo inmobiliario en todas sus fases: financiamiento del terreno, de la construcción y de la compra de las viviendas. Esto implica una mayor celeridad para la reventa de los terrenos al desarrollador (Gasic, 2018).

Dicha lógica no es fácilmente extensible a las aseguradoras ya que no entregan créditos a la construcción, aunque sí pueden tener otros intereses en el desarrollo inmobiliario asociado a bonos, acciones e incluso letras hipotecarias si se quiere vincular con la activación de la demanda. A diferencia de los bancos, que entregan financiamiento a todo el proceso, las aseguradoras tienen un mayor interés en mantener los terrenos en leasing o leaseback, dado que esto asegura la generación de flujos de renta a mediano y largo plazo para hacer calzar sus obligaciones financieras, particularmente aquellas ligadas al pago de las rentas vitalicias (García, 2018). Al observar la localización espacial de las transacciones de bancos y aseguradoras se refuerza esta afirmación dado que éstas concentran sus adquisiciones en el área periurbana de Santiago (68\% del total), mientras los bancos tienen un comportamiento espacial disperso entre las distintas áreas de la ciudad (Gasic, 2016).

Por su parte, hay una orientación muy diferenciada entre bancos y aseguradoras en lo que respecta a los agentes económico-sociales a los que se les vende los terrenos. Mientras los bancos venden un tercio de los terrenos a personas naturales, las aseguradoras no llegan al $8 \%$. La relación se invierte si se observan las ventas a sociedades de inversión, ya que, mientras las aseguradoras venden un $27,6 \%$ a estas entidades, los bancos solo llegan a $9 \%$. De forma más agregada se puede notar que las aseguradoras venden un $84 \%$ de sus terrenos a agentes financieros o inmobiliarios, considerando constructoras; mientras los bancos concentran solo un $40 \%$ de sus ventas en los agentes financiero-inmobiliarios. Estableciendo una matriz de relaciones de 
compra-venta el resultado es indiscutible: los bancos hacen factoring con los terrenos de diversos tipos de sociedades, instituciones, empresas y personas naturales que requieren liquidez, mientras las aseguradoras se orientan focalizadamente en el financiamiento al sector inmobiliario y otros financieros.

Dado lo anterior, el rol específico de las aseguradoras en la generación de reservas de suelo específicamente para desarrollo inmobiliario debe estudiarse más detenidamente, ya que representa un alto porcentaje de sus operaciones en el mercado del suelo y muestran una tendencia a la generación de flujos de mediano y largo plazo. Para ello es necesario centrar el análisis en la intermediación de terrenos que fluyen directamente a la ejecución de proyectos inmobiliarios, como muestra el apartado siguiente.

\section{Estimación de las ganancias de capital y las rentas en la intermedia- ción de terrenos para desarrollo inmobiliario de casas}

Al realizar este análisis de integración de terrenos al desarrollo inmobiliario capitalista se corrobora la importancia de la diferencia anteriormente establecida entre inversionistas y financieros. El Cuadro $\mathrm{N}^{0} 3$ muestra el diferencial de precio de compra y venta que generan los intermediadores de aquellos terrenos que se insumen en el desarrollo de los proyectos, y en ella se puede observar que, en el caso de los proyectos inmobiliarios intermediados por sociedades de inversión, los diferenciales de precio son relativamente mayores que en aquellos casos donde participan bancos y aseguradoras, y cuando el diferencial no solo es sustantivamente menor, sino que registra incluso valores negativos.

De hecho, en los dos proyectos donde operan bancos, se observa que el precio al que compra la inmobiliaria que ejecuta el proyecto es menor al que compró el banco, lo que resulta difícil de explicar más allá de que pueda tratarse de operaciones sin éxito. Tanto los bajos diferenciales como sus diferenciales negativos deben ser comprendidos como parte de una lógica financiera en donde la intermediación de terrenos no genera ganancias de capital por la compraventa, sino por las rentas que reportan los contratos de Leasing durante los períodos en que los agentes financieros retienen las propiedades, por lo que las intermediaciones de terrenos de bancos y aseguradoras no empujan hacia arriba los precios del suelo al que compran las empresas inmobiliarias.

Estos resultados son consistentes con lo que se muestra en los reportes anuales de las principales aseguradoras que participan del mercado del suelo. Mientras las rentas anuales que cobran como tasa de interés por los Leasing tienen una media de 6,7\% en contratos generalmente por sobre los 15 años, las ganancias de capital por las reventas de los terrenos son a veces negativas, incluso llegando a un -7\% sobre la inversión inicial. De esta forma, se corrobora que estas operaciones tienen por objeto principal la generación de flujos de renta a mediano y largo plazo, sobre todo para las aseguradoras que deben calzar sus obligaciones de pago de rentas vitalicias y no se dedican al financiamiento de la construcción de los proyectos (Mogrovejo, 2016). 
Cuadro N³. Variación de precio en la reventa de terrenos a desarrolladores inmobiliarios según tipo de entidad intermediaria.

\begin{tabular}{|l|c|}
\hline \multirow{2}{*}{ Entidad } & Variación de precio del suelo por proyecto $\left(\mathrm{UF} / \mathrm{m}^{2}\right)$ \\
\hline \multirow{4}{*}{ Aseguradora } & $-0,017$ \\
\cline { 2 - 2 } & $-0,951$ \\
\hline \multirow{3}{*}{ Inversionista } & 0,051 \\
\cline { 2 - 2 } & 0,707 \\
\cline { 2 - 2 } & $-0,104$ \\
\cline { 2 - 2 } & 0,981 \\
\cline { 2 - 2 } & 0,101 \\
\cline { 2 - 2 } & 0,804 \\
\hline \multirow{2}{*}{ Aseguradora + Inversionista } & 0,966 \\
\hline Empresa Leasing & 0,024 \\
\hline Persona Natural & 0,610 \\
\cline { 2 - 2 } & 0,023 \\
\hline
\end{tabular}

Fuente: elaboración propia en base a datos de Conservadores de Bienes Raíces de la Región Metropolitana (2017). *Cada fila es un proyecto distinto intermediado por cada tipo de entidad respectiva.

\section{Períodos de retención e incorporación de terrenos para el desarrollo inmobiliario de casas}

Precisamente por lo anterior se han observado los períodos en los que se retienen los terrenos por parte de los intermediarios financieros en los 28 proyectos de casas seleccionados. La Figura No7 muestra que, en promedio, los proyectos mantienen los terrenos en un lapso de nueve años desde que se comienza a comprar los terrenos hasta que se inician las obras, lo que se extiende hasta por once años, cuando se inicia la ejecución de las últimas etapas de los proyectos. Por su parte, se observa una fase de reserva de terrenos, que comprende desde el inicio del proceso hasta la adquisición del último predio por parte de la empresa desarrolladora, la cual se extiende en promedio 6,1 años. Aproximadamente 2,8 años dura la incorporación de los terrenos por parte de las empresas desarrolladoras, desde que adquieren el último predio hasta que inician las obras de la primera etapa del proyecto.

Estos datos son meramente exploratorios, y es difícil extender de ellos reflexiones de carácter explicativo. Sin embargo, hay dos elementos que interesan a este trabajo. Por una parte, los plazos a los cuales se retienen los terrenos no son tan largos como pudiese esperarse. Esto podría deberse a que la retención de terrenos sea realizada por grandes propietarios originales con capacidad de esperar los ciclos altos de apreciación de los terrenos. Es necesario reconocer que la función de retención de terrenos para desarrollo inmobiliario puede ser realizada, en algunos casos, por grandes propietarios cuando la reestructuración geográfica que genera el mercado no los fuerce a vender, como en casos donde empresas agrícolas venden sus terrenos para relocalizarse a tiempo. En cualquier caso, el tiempo medio de 6 años en la intermediación de terrenos de los 28 
proyectos seleccionados está bastante bajo la media de los contratos de leasing y leaseback de las aseguradoras, los cuales superan en promedio los 15 años de duración. Esto puede deberse a un problema de representatividad de la muestra, pero también al hecho de que muchos de los grandes terrenos comprados por aseguradoras o bancos son revendidos solo parcialmente a los desarrolladores, conforme van ejecutando los proyectos y vendiéndolos diferenciados por etapa.

Un segundo elemento notable es que no se observan diferencias entre los tiempos de reserva de terrenos de bancos, aseguradoras e inversionistas. Se podría esperar que los bancos tengan menos tiempo sobre los terrenos, dado que parte de su negocio consiste en el desarrollo de los proyectos, financiando la construcción. En cambio, las aseguradoras no tienen esa componente en su negocio, sino que suelen establecer contratos de leasing entre 5 y 25 años con el fin de extender un flujo largo para el pago de rentas vitalicias, que es parte de su negocio central como rubro. No obstante estas consideraciones, los proyectos intermediados por estos diferentes agentes muestran tiempos similares en las operaciones.

Figura N07. Períodos de tiempo entre las fases de reserva, incorporación y desarrollo de terrenos urbanos en proyectos de casas analizados.

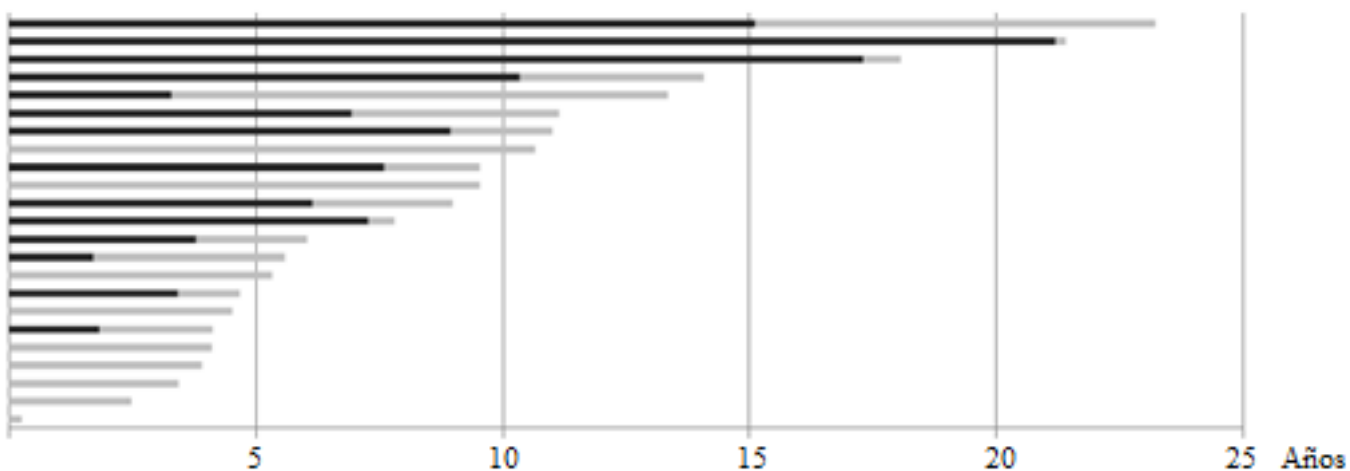

Fuente: elaboración propia en base a datos de Conservadores de Bienes Raíces de la Región Metropolitana (2017). *Las barras en negro representan el tiempo en la fase de reserva y las barras en gris representan el tiempo en la fase de incorporación, medidos en años.

\section{Discusión y principales resultados}

Los resultados a la fecha obtenidos indican que el mercado del suelo del AMS está altamente mediado por agentes del rubro de intermediación financiera, a tal punto que las adquisiciones de terrenos por parte del conjunto de entidades de este rubro son incluso mayores que las correspondientes al rubro inmobiliario. Asimismo, se confirma la importancia gravitante del sector financiero en el flujo de terrenos que se incorporan al desarrollo inmobiliario capitalista al mediano y largo plazo, mejorando la circulación de las propiedades hacia el sector, cobrando tasas de interés por períodos de tiempo relativamente largos, y funcionando incluso sin que existan ganancias de capital asociadas a la valorización inmobiliaria propiamente tal -lo que se constató al estimar las ganancias de capital obtenidas de los terrenos intermediados en los proyectos analizados. 
Para arribar a dicha conclusión este estudio ha focalizado la observación en bancos y aseguradoras, los cuales conforman un robusto sector de la economía financiera orientado a intermediar las compras de terrenos de los desarrolladores inmobiliarios, cobrando un interés por el costo de retener las propiedades. Para ello ambas entidades frecuentan el uso de instrumentos de leasing y leaseback, con los cuales arriendan a plazo definido los terrenos a los desarrolladores y luego se los revenden cuando éstos lo requieran. Dichos instrumentos deben ser entendidos como piezas clave de lo que son las formaciones de reservas de suelo en las ciudades altamente financiarizadas. Si bien no corresponden a instrumentos especulativos en el sentido de funcionar mediante precios de expectativas, sí corresponden con la lógica financiera de anticipar fondos para la producción inmobiliaria futura.

En el caso de las aseguradoras, establecen contratos de leasing y leaseback con cánones de arriendo fijados como tasa de interés sobre el capital invertido en la compra del suelo. El negocio consiste en alargar los flujos de renta y calzar con sus obligaciones financieras, estableciendo contratos de leasing que en promedio superan los 15 años. Consistente con ello, localizan sus operaciones en áreas periurbanas de menor consolidación, constituyendo reservas de suelo en las áreas que se incorporarán al desarrollo urbano en el futuro próximo, anticipando su incorporación a la dinámica de las empresas inmobiliarias de casas en Santiago.

A diferencia, los bancos mantienen una estrategia de negocio que integra distintas fases del desarrollo inmobiliario, incluido muchas veces los créditos a la construcción. Por ende, se espera contratos más cortos y orientados a la venta pronta del terreno, aun cuando los datos de tiempo de las operaciones que se han recolectado a la fecha no muestran esta tendencia (huelga notar aquí que falta una recolección más representativa de datos en este ítem específico del estudio). No obstante, su menor orientación a la compra de terrenos periurbanos, su estrategia de valorización de capitales en la producción de las viviendas y su estructura de relaciones con entidades no inmobiliarias los distancian del rol que cumplen las aseguradoras en la financiarización del suelo en esta ciudad.

Pero lo cierto es que cuantitativamente el conjunto de operaciones de bancos y aseguradoras es menor que aquellas transacciones realizadas por otro tipo de entidad financiera: las sociedades de inversión. Éstas canalizan financiamiento a la compra de terrenos, sea con participación de las mismas empresas inmobiliarias o de manera totalmente externa como inversionistas con expectativa de alza del precio del suelo y obtención de ganancias de capital por la reventa de las propiedades. Estas prácticas de inversionistas no han sido abordadas en este estudio dado que representan un grupo muy heterogéneo, a veces correspondientes a figuras legales dependientes de grandes empresas inmobiliarias, lo que hace difícil distinguirlas de las empresas matrices.

Si bien las sociedades de inversión no se han abordado focalizadamente en este trabajo, es importante destacar la importancia que eventualmente pueden tener, sobre todo en caso de que operen con relativa autonomía respecto a los desarrolladores. Esto dado que la lógica de adquisición anticipada de terrenos y consecuente sobre-apreciación de los mismos ha sido reportada para el caso de Estados Unidos en el período 2000-2007, con alta incidencia en la generación de la burbuja inmobiliaria norteamericana (Gaffney, 2009; Hudson, 2010). En este sentido la gran cantidad de terrenos adquiridos por sociedades de inversión representa un fenómeno especial- 
mente atractivo para estudios de financiarización asociados a mayor riesgo y volatilidad de los mercados inmobiliarios (Gasic, 2016).

En su conjunto, este trabajo ha considerado que las prácticas de reserva de suelo deben ser vinculadas a los procesos generales de financiarización de la economía mundial y chilena. El incremento de la disponibilidad de capitales provenientes del sector financiero -bancario y asegurador, al menos- al desarrollo inmobiliario capitalista a mediano y largo plazo se explica, en parte, por el menor costo que tienen las grandes entidades financieras para retener sus capitales en la forma de activos inmobiliarios en un contexto mundial de menor rentabilidad de las inversiones en el sector productivo (Foster, 2010; Hudson, 2010). De esta manera se van formando reservas que funcionan como activos inmobiliarios de grandes conglomerados financieros, tal como ha sido observado también por otros analistas e investigadores de alcance internacional (Harvey, 1974; Hudson, 2010; Christophers, 2017).

Sobre los efectos sociales del proceso económico-urbano que aquí se estudia, cabe indagar en próximas investigaciones sobre las relaciones entre la formación de reservas de suelo y las dinámicas excluyentes y segregadoras del mercado del suelo urbano. En general todos reconocen la dificultad de costear terrenos para fines de interés social, pero atribuyen el problema al "mercado" y a la formación de precios por la demanda habitacional del submercado más dinámico de los grupos altos y medios. No obstante, ha sido escasamente estudiado el efecto que tiene sobre el precio del suelo la penetración cada vez más profunda del sector financiero y de inversionistas. Podría plantearse que, ceteris paribus los ingresos de la población y la capacidad de endeudamiento de los hogares, el suelo urbano está encareciéndose por la acción de nuevos inversionistas e intermediarios financieros que inhiben el flujo de terrenos a usos distintos al que dispone el mercado inmobiliario de mayor rentabilidad.

Lo que aquí se plantea es que adquisiciones por leasing a 20 años revelan una restricción de mercado, sea o no conceptualizable como oligopolio. Dicho de otra forma, es probable que mucho de lo que se asume como suelo disponible en el mercado no sea sino capital inmobiliario que, en la forma de terrenos urbanos, ya están valorizados por las empresas que luego encargan la construcción y comercializan las viviendas y otros productos inmobiliarios. Representa una forma financiera de retener suelo en la ciudad y sus efectos sociales pueden ser incluso más regresivos dado que se refuerza el rol socialmente excluyente de la propiedad del suelo urbano.

A su vez, la formación de reservas financieras de suelo representa una nueva encrucijada para la política y las políticas públicas. Esto dado que no es lo mismo intervenir la propiedad del suelo cuando se afectan ganancias de propietarios rentistas que cuando se afecta el capital invertido para obtener intereses sobre el arrendamiento financiero de una propiedad. Hipotéticamente ¿cómo aplicar Instrumentos de Captura de Plusvalías inmobiliarias -por ejemplo- si el suelo urbano ya es de propiedad de bancos y aseguradoras, considerando que éstos solo obtienen un interés por la retención del suelo y no una renta o ganancia de capital derivada de la valorización inmobiliaria?

Considerando la discusión vigente sobre instrumentos recaudatorios y/o de financiamiento urbano como los Instrumentos de Captura de Plusvalías, surge la pregunta sobre cómo afectarían dichas medidas al circuito de acumulación de capital financiero en el país, dada la participación 
de bancos, aseguradoras y sociedades de inversión en el mercado del suelo. Asimismo, la aparente voluntad del Consejo Nacional de Desarrollo Urbano por implementar un banco de suelo público debería considerar también que -como muestra este trabajo- el sector financiero privado ya se encuentra formando importantes reservas y que, por ende, la formación de reservas públicas difícilmente podría estar ajena a una competencia de mercado por suelo a mediano y largo plazo. Todos estos elementos podrían ser incorporados a una amplia discusión sobre los efectos sociales, económicos y políticos de la formación de reservas privadas de suelo urbano en Chile, o al menos en Santiago.

\section{Bibliografía}

CATTANEO, R. Los fondos de inversión inmobiliaria y la producción privada de vivienda nueva en Santiago de Chile ¿un nuevo paso hacia la financiarización de la ciudad? EURE, 2011, Vol. 37, Nº 112 , p. 5-22.

CEHU. Crecimiento urbano: un modelo de proyección para Chile. Documento de Trabajo $N^{\circ} 23$, Santiago de Chile: Centro de Estudios Habitacionales y Urbanos, 2013.

CHRISTOPHERS, B. The State and financialization of public land in the United Kingdom. Antipode, 2017, Vol. 49, No 1, p. 62-85.

CNDU. Propuestas para una Política de Suelo para la Integración Social Urbana. Informe Final. Santiago de Chile: Comisión Nacional de Desarrollo Urbano, 2015.

COX, P. \& PARRADO, E. Evolución de los precios de la vivienda en Chile. Publicado en el Informe de Estabilidad Financiera del Banco Central de Chile. Santiago de Chile: Banco Central de Chile, 2005.

DE GREGORIO, J. Crecimiento económico en Chile: evidencia, fuentes y perspectivas. Centro de Estudios Públicos, 2005, 98, p.19-86.

DE MATTOS, C. Globalización financiera, dinámica inmobiliaria y mercantilización del desarrollo urbano. Documento de Trabajo, Proyecto Fondecyt $N^{\circ} 1110387$. Santiago de Chile: Pontificia Universidad Católica de Chile, 2013.

DE MATTOS, C. Financiarización, valorización inmobiliaria del capital y mercantilización de la metamorfosis urbana. Revista Sociologías, 2016, Vol. 18, № 42, p. 24-52.

EDWARDS, G., HURTUBIA, J. \& WAGNER, G. El suelo urbano y el mercado de activos. Documento de Trabajo $N^{\circ} 177$. Santiago de Chile: Instituto de Economía, Pontificia Universidad Católica de Chile, 1995.

FOSTER, J.B. The financialization of accumulation. Monthly Review, 2010, Vol. 62, N5. Disponible en internet: https://monthlyreview.org/2010/10/01/the-financialization-of-accumulation/ 
GAFFNEY, M. The Role of Land Markets in Economic Crises. American Journal of Economics and Sociology. American Journal of Economics and Sociology, 2009, Vol. 68, № 4, p. $855-888$.

GARCÍA, N. Financiamiento de activos inmobiliarios en Chile. En: SIMIAN, J. y NIKLITSCHEK, V. La Industria Inmobiliaria en Chile: Evolución, Desafíos y Mejores Prácticas. Santiago de Chile: Pearson Educación de Chle, S.A., 2017, p. 675-698.

GASIC, I. Mercado del suelo y producción inmobiliaria en Santiago. Tesis para obtener el grado académico de Magíster en Desarrollo Urbano. Santiago de Chile: Pontificia Universidad Católica de Chile, 2016.

GASIC, I. Inversiones e intermediaciones financieras en el mercado del suelo urbano. Principales hallazgos a partir del estudio de transacciones de terrenos en Santiago de Chile, 2010-2015. EURE, 2018, Vol. 44, No 133 , p. 29-50.

HARVEY, D. Class-monopoly rent, finance capital and urban revolution. Regional Studies, 1974, N 8, p. 239-255.

HUDSON, M. The Transition from Industrial Capitalism to a Financialized Bubble Economy. Working paper $N^{\circ}$ 627. New York: Levy Economics Institute of Bard College, 2010.

INCITI. Ranking de Promotores Inmobiliarios, Región Metropolitana de Santiago. Santiago de Chile: Inciti Consultores, 2016.

JARAMILLO, S. Hacia una teoría de la renta del suelo urbano. Bogotá: Centro de Estudios sobre Desarrollo Económico CEDE-Universidad de Los Andes, 2009.

LÓPEZ-MORALES, E. Gentrificación en Chile: aportes conceptuales y evidencias para una discusión necesaria. Revista de Geografía Norte Grande, 2013, 56, p. 31-52.

LÓPEZ-MORALES, E. Gentrification in Santiago, Chile: a property-led process of dispossession and exclusion. Urban Geography, 2016, Vol. 37, № 8, p.1109-1131.

MARX, K. El Capital Tomo III: el proceso global de la producción capitalista. Siglo XXI de España Editores S.A., 1981.

MOGROVEJO, R. Entrevista a Roger Mogrovejo, Gerente de Inversiones en Metlife entre 2013 y 2016, y en Principal Financial Group desde 2016. Realizada por Ivo R. Gasic Klett en el marco del proyecto Fondecyt 1141157, Santiago de Chile, 2016.

OCDE. Estudios económicos de la OCDE Chile, 2015.

RICARDO, D. Principios de Economía Política y Tributación. Volumen 1. Barcelona: Ediciones Orbis S.A., 1985. 
SABATINI, F. \& DONOSO, F. La renta de la tierra en el desarrollo residencial reciente de Santiago. Documento de Trabajo CIDU-IPU. Santiago de Chile: Pontificia Universidad Católica de Chile, 1979.

SABATINI, F.\& DONOSO, F. Algunas hipótesis sobre la importancia de la renta de la tierra en el desarrollo reciente de Santiago. Documento de Trabajo CIDU-IPU. Santiago de Chile: Pontificia Universidad Católica de Chile, 1980.

SMITH, A. Investigación sobre la Naturaleza y Causas de la Riqueza de las Naciones. Edición Conmemorativa del Bicentenario de la Primera Edición de la Obra. Barcelona: Oikos-tau S.A., 1981.

THEURILLAT, T. The negotiated city: between financialization and sustainability. Working paper within the framework of the Swiss National Research Project PNR 54 on the Sustainable development of the built environment: FN 405440-115136/1. Neuchâtel, Switzerland: University of Neuchâtel, 2012.

TRIVELLI, P. Urban structure, land markets and social housing in Santiago, Chile. Working Paper BID. Santiago de Chile: Banco Interamericano de Desarrollo, 2010.

TRIVELLI, P. La propuesta de modificación del Plan Regulador Metropolitano de Santiago PRMS 100 requiere una justificación más sólida. EURE, 2011, Vol. 37, № 111, p. 179-184. 